\title{
Analytical Study the Performance Evaluation of Mobile Ad Hoc Networks using AODV Protocol
}

\author{
Rajan Bansal \\ M.Tech (CSE) \\ BMSCE Muktsar, 152026, India
}

\author{
Himani Goyal \\ Principal \\ BMSCE Muktsar, 152026, India
}

\author{
Parminder Singh \\ Senior Lecturer \\ CEC Landran, 140307,India
}

\begin{abstract}
The mobile Ad hoc networks (MANETs) have been communicating over wireless mesh channels and support multihop networks. Every node in the MANET is free to move independently in any of direction. MANET is a kind of wireless mesh networks which operates in Link Layer (LL) of Ad hoc networks. The current network scenarios consist of combined wired and wireless links which demands for investigating the performance in such mesh scenarios. This Paper investigates the performance evaluation of MANET over 802.11 wireless networks. MANET also uses TCP/IP structure to provide communication between different moving nodes. The impact of mobility or ad hoc routing protocols and different versions of TCP behave differently in this mobile environment and result obtained thereof has been presented in the form of important TCP metric. This paper further investigates the packet sequence traces in the wireless networks. We also use AODV routing protocols, perform best and less overhead in large networks. The different tools have been used to show the important TCP metrics such as Gnuplot, Perl and Python scripts.
\end{abstract}

Keywords: Mobile ad hoc Networks, Link Layer, TCP/IP AODV, Throughput.

\section{INTRODUCTION}

A network is defined as the group of systems who tend to share their information collectively for their business purpose. A network can be characterized as wired or wireless. Wireless can be distinguished from wired as no physical connectivity between nodes are needed. Wireless network is a network set up by using radio signal frequency to communicate among computers and other network devices. Sometimes it's also referred to as WiFi network or WLAN. With the advances of wireless communication technology, low cost and powerful wireless transceivers are widely used in mobile application. Mobile networks have attracted significant interests in recent years because of their improved flexibility and reduced cost. In mobile networks node mobility may cause frequent network topology changes. In wireless link capacity continually varies because of impacts from transmission power, receiver sensitivity, noise, fading and interference.

The IEEE 802.11 standards specify two operating modes: infrastructure mode and ad hoc mode. Infrastructure mode is used to connect computers with wireless network adapters, to an existing wired network with the help from wireless router or access point. The access points compose the backbone for infrastructure network. Ad hoc mode is used to connect wireless clients directly together, without the need for a wireless router or access point.

A mobile ad hoc network is an autonomous system of mobile routers connected by wireless links. In MANET nodes can perform the roles of Host and Router. Mobile ad hoc networks are self organizing and self configuring multihop wireless networks. The routers are free to move randomly and organize themselves. In MANET dynamic network topology is used with frequent routing updates. MANET normally has limited transmission ranges of nodes, so some nodes cannot communicate directly with each other. Routing path in MANET potentially contain multiple hops. In multi-hop routing network should be able to maintain path to other nodes and must handle changes in path due to mobility. In MANET have routing problem because topology of MANET is not constant, routing tables must somehow reflect these changes in topology and routing algorithms have to be adapted.

Routing is the act of moving information from source to a destination in an internetwork. The routing concept basically involves two activities: firstly determining optimal path and secondly transferring groups through an internetwork. In MANET have routing problems to transfer the packets from source to destination due to Interference, asymmetric links and dynamic topology. Routing protocols in MANET can be done in many ways, but most of these are depending on routing strategy and network structure. There are basically two routing protocols are used: Proactive (Table-driven and Reactive(On-demand). In proactive protocols maintain the routing information even before it is needed. Each and every node in network maintains information to every other node in network e.g. DSDV. In Reactive protocol doesn't maintain routing information at the network nodes if there is no communication. If node a node wants to send a packet another node this protocols search for the route in an on-demand manner e.g. AODV.

\section{AODV PROTOCOL}

In on-demand routing protocols a fundamental requirement for connectivity is to discover routes to a node via flooding of request messages. Reactive protocols don't maintain routing information at the network nodes if there is no communication. AODV is very efficient and effective routing protocol for MANET which do not have fixed topology. The AODV means Ad hoc on demand distance vector routing protocol. The ad hoc means there is no fixed or base station is needed. AODV determines route when node wants to communicate with destination and its also guarantee the loop-free routing. Each node is communicating with other node via multiple wireless links and the nodes works as a router to route the packets from one node to another node.

The AODV protocol works as to send a message, the data source initiates a path-discovery process in order to find the route. The route request packet (RREQ) is flooded to the network and the intermediate nodes record the neighbour from which they get the RREQ first, in order to establish reverse paths back to the source. When the RREQ arrives at the destination, it then sends back a 
route reply (RREP) to the source following those reverse paths. AODV needs symmetric links; otherwise the RREP may not be able to reach the source and AODV would fail.

Dijktsra's algorithm is called the single-source shortest path. It computes of the shortest path from the source to each of remaining vertices in the graph. Using Dijktsra's algorithm we find shortest path in AODV routing protocol. Shortest path is find through Dijkstra's algorithm.

\section{RELATED WORK}

The aim of this paper to test the AODV protocol and investigating the effects of inter router distance. We also study the AODV protocol used only in wireless networks but some problems associated with wired networks within MANET. To improve this some modification done in this protocol to work both wired and wireless networks.

The evaluation has been according to the following metrics:

- Throughput of MANET.

- Packet sequence traces over a wireless networks.

\section{EXPERIMENT METHODOLOGY}

This paper uses NS2 simulator for evaluating the performance of AODV protocol using MANETs. The simulator has been used by oTCL and c++ languages. The simulation time is set to 1000 seconds. The studied scenario consists of 20 mobile stations connected with two gateways, routers and hosts. The isosceles triangle shows the gateway, rectangle shows the host and routers and the small circles represent the different mobile nodes moving within the whole network. AODV protocol works on the network layer whereas the traffic randomly distributed on the MANET. This section represents the simulation scenario shown in figure 1. The packet size was 512 bytes and work on 802.11 networks. Each mobile node has been freely to move and communicating with each other via different hosts.

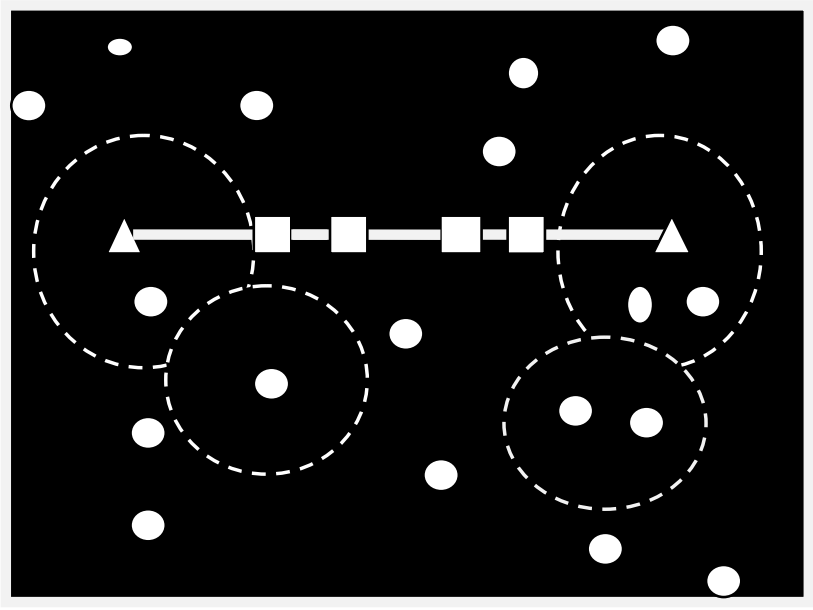

Figure 1: Simulation Scenario of MANET

\section{RESULTS AND DISCUSSIONS}

In this section, we find different performance metric results run under network simulator. The figure 2 shows, performance graph of throughput. This architecture works on wired cum wireless networks and the communication between different gateways.

The following table shows the default parameters of AODV protocol shown in the table1 [3]. The parameter MY_ROUTE_TIMEOUT lifetime shows the expiration or deletion time of the route and the station to process a packet by using NODE_TRAVERSAL_TIME.

Table 1: Default values of AODV Protocol [3]

\begin{tabular}{|l|l|}
\hline Parameter & Value \\
\hline MY_ROUTE_TIMEOUT & 10 seconds \\
\hline ACTIVE_ROUTE_TIMEOUT & 10 seconds \\
\hline REV_ROUTE_LIFE & 6 seconds \\
\hline BCAST_ID_SAVE & 6 seconds \\
\hline NODE_TRAVERSAL_TIME & 30 hops \\
\hline NODE_TRAVERSAL_TIME & 30 ms \\
\hline RREQ_RETRIES & 2 \\
\hline MAX_RREQ_TIMEOUT & 10 seconds \\
\hline TTL_START & 1 \\
\hline TTL_INCREMENT & 2 \\
\hline TTL_THRESHOLD & 7 \\
\hline
\end{tabular}

The table 2 shows the gateway parameters that are associated with simulated scenario [3]. The negative value is chosen of the DEFAULT and ALL_MANET_GW_MULTICAST parameter that cannot mixed with the address of the mobile station.

Table 2: Gateway Parameters [3]

\begin{tabular}{|l|l|}
\hline Parameter & Value \\
\hline DEFAULT & -10 \\
\hline ALL_MANET_GW_MULTICAST & -20 \\
\hline GWINFO_LIFETIME & 10 seconds \\
\hline ADVERTISEMENT_INTERVAL & 5 seconds \\
\hline ADVETISEMENT_ZONE & 3 hops \\
\hline
\end{tabular}

The following simulation parameter of MANET is shown in Table3. The number of gateway is two with transmission range 250 millisecond (ms). The number of randomly mobile station is 36 with area $1000 \mathrm{~m} \times 1000 \mathrm{~m}$. The data rate is set to $2 \mathrm{Mbps}$ and number of gateways is two that communicating with different mobile stations as shown in scenario (Figure 1). The all simulation parameters set in script file and run on network simulator and result is calculated through different scripts. 
Table 3: Simulation Parameters of MANET

\begin{tabular}{|l|l|}
\hline Parameter & Value \\
\hline Topology Area & 1000 meter x 1000 meter \\
\hline $\begin{array}{l}\text { Number of mobile } \\
\text { stations }\end{array}$ & 36 \\
\hline Transmission range & $250 \mathrm{~ms}$ \\
\hline $\begin{array}{l}\text { Number of } \\
\text { gateways }\end{array}$ & 2 \\
\hline Data rate & 2 Mbps \\
\hline Packet size & 512 Bytes \\
\hline Simulation Time & 500 seconds \\
\hline
\end{tabular}

The figure 2 represents the throughput of MANET that represents with using Perl script. The Y-axis shows throughput in kilobytes and $\mathrm{X}$-axis shows time. The red line of the graph shows the best effort and green represents the voice transmission. We start a best effort approximately started at $70 \mathrm{~s}$ and going on until $120 \mathrm{~s}$. The following figure shows the throughput over time. The throughput is calculated as total bytes received by the destination node per second. The delay is more when the communication between the nodes is no more and the throughput is nil. When the different nodes have been communicating with each other then it start over $70 \mathrm{~s}$. The data is more stable when AODV protocol is run. It also shows when the network topologies have been changed then AODV protocol is mostly used because the data remains stable.

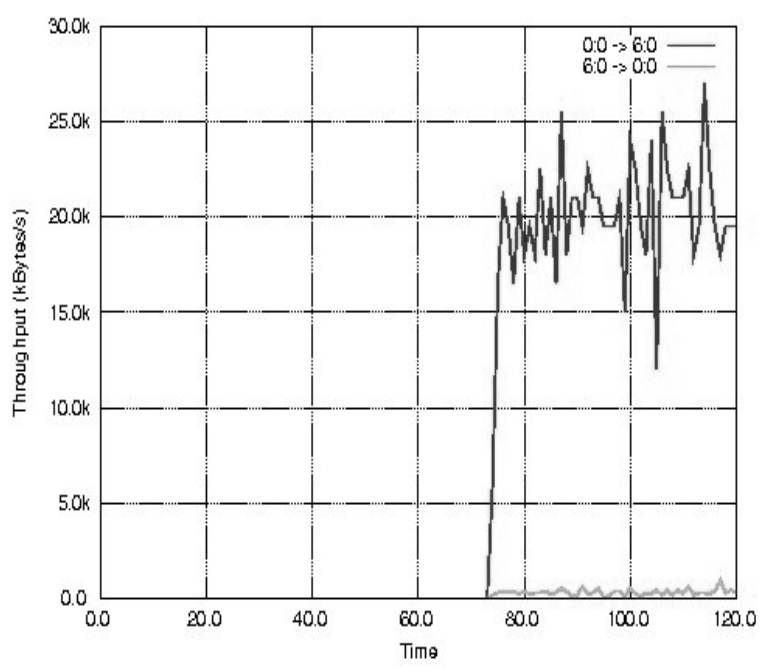

Figure 2: Throughput of MANET

The figure 3 represents the packet sequence traces. The wireless part has shown in horizontal, it represents the sequence number and the bottom one the time in seconds that continuously fluctuated due to wireless medium. This graph represented by using Gnuplot.

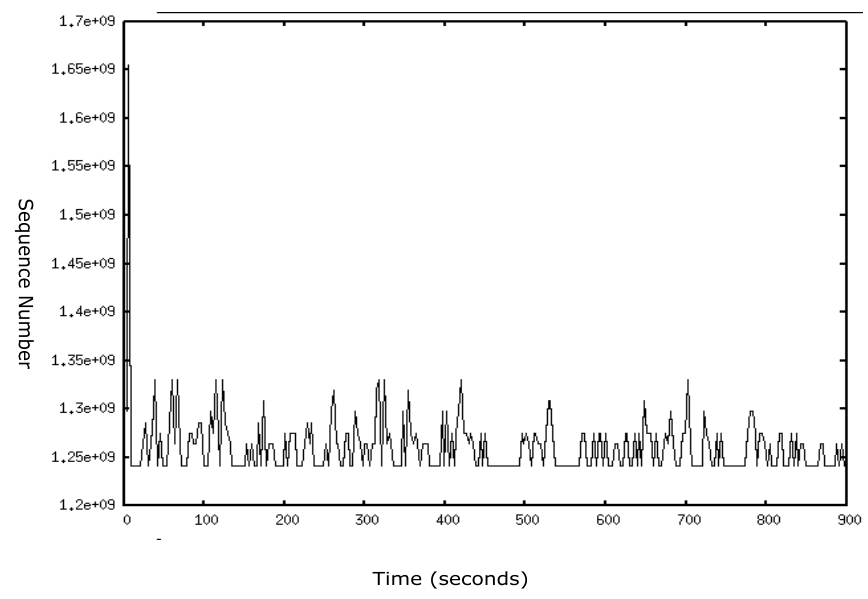

Figure 3: Packet sequence trace

The Table 4 shows the shortest path. The value shows different shortest path from different grids. The different values have been shown by using different parameters such as heuristic, single path and shortest path only. The calculation is done with the help of python script that run under NS2 tool. To route the packets from all the hops is calculated 2.903264. This value is shown above is the time to send packet by the source node to destination node. Where the number of nodes is communicating with each other and the packets is move between each node that the time is calculated.

Table 4: Simulation for different shortest path

\begin{tabular}{|l|l|l|l|}
\hline Parameter & 3x3 Grid & 6x6 Grid & $\begin{array}{l}\text { 36 node } \\
\text { Randomly }\end{array}$ \\
\hline $\begin{array}{l}\text { Shortest path } \\
\text { (for single } \\
\text { path) }\end{array}$ & 0.640732 & 106.983294 & 27.101430 \\
\hline $\begin{array}{l}\text { Shortest path } \\
\text { heuristics }\end{array}$ & 0.646708 & 37.721666 & 4.366340 \\
\hline Shortest path & 0.388464 & 9.264742 & 2.613086 \\
\hline
\end{tabular}

\section{CONCLUSION}

This paper using network simulation tool, we obtained different graphs and analyzed the results. We present a scenario that works well over wired and wireless networks where some modification was done on the AODV protocol. To achieve this mobile nodes communicating within the MANET networks. The AODV protocol used in MANET to traces the packet sequences and shows some fluctuation on the wireless medium.

We also show the results to find the single shortest path that represented in table. We can see that it adapts quickly to the change of the network and has a relatively stable throughput with a moderate good put. So, in an application where there is a fast change in the network topology and a requirement of stable date rate therefore, AODV is more preferable. 


\section{REFERENCES}

[1] A. Nasipuri, J. Mandava, H. Manchala, and R. E. Hiromoto, "On-demand routing using directional antennas in mobile ad hoc networks", ICCCN, 2000, pp.535 - 541.

[2] A. Nasipuri, S. Ye, J. You, and R. E. Hiromoto, "A MAC protocol for mobile ad hoc networks using directional antennas", IEEE WCNC, 2000, pp. 1214 - 1219.

[3] Ali Hamidian, Claudio E. Palazzi, Tin Y. Chong, Juan M. Navarro, Ulf Körner, Mario Gerla, "Deployment and Evaluation of a Wireless Mesh Network",IEEE,2009,pp.6672

[4] C. Perkins, E. M. Belding-Royer and S. Das. "Ad hoc OnDemand Distance Vector (AODV) Routing”. Experimental RFC 3561.

[5] David Kotz and Kobby Essien, “ Analysis of a campus-wide wireless network. Technical Report TR2002-432, Dept. of Computer Science, Dartmouth College, 2002.

[6] Deng H, Li W, Agrawal DP (2002), "Routing Security in Wireless Ad Hoc Networks. IEEE Communications Magazine", Volume 40, Issue 10:70-75

[7] H. Harada and R. Prasad, "A New Multi-carrier CDMA/TDD Transmission Scheme Based on Cyclic Extended Spread Code for 4th Generation Mobile Communication System," in Proceedings of the IEEE International Conference on Personal Wireless Communication Conference, pp. 319-323, 1997

[8] J. Broch, D. A. Maltz, D. B. Johnson, Y.-C. Hu, and J. Jetcheva, "A Performance Comparison of Multihop Wireless Ad Hoc Network Routing Protocols," in Proceedings of the Fourth Annual ACM/IEEE International Conference on Mobile Computing and Networking (Mobi-Com'98), pp. 8597, 1998.

[9] K.Kyungtae and H. Sangjin, "VoMESH: voice over wireless mesh networks," in Proc. of IEEE WCNC, Las Vegas, NV, USA, 2006, pp. 193-8.

[10] L. Bononi and A. Boukerche, "Simulation and Modeling of Wireless, Mobile and Ad Hoc Networks," in Mobile Ad Hoc Networking, S. Basagni, M. Conti, S. Giordano, and I. Stojmenovic (Eds.), IEEE-John Wiley, 2004.
[11] Li Q, RusD(2000) Sending messages to disconnected users in disconnected ad hoc mobile networks. Proc 6th Annual ACM/IEEE Intl Symp on Mobile Computing and Networking (MobiCom), 44-55

[12] M. S. Corson and J. Macker, "Mobile Ad Hoc Networking (MANET): Routing Protocol Performance Issues and Evaluation Considerations," RFC 2501, IETF, January 1999.

[13] McDonald, A. B., and T. F. Znati, "A mobility-based framework for adaptive clustering in wireless ad hoc networks," IEEE Journal on Selected Areas in Communications, vol. 17, no. 8, pp. 1466-1487, Aug. 1999.

[14] Mohsen Guizani," Wireless Communications Systems and Networks", Kluwer Academic Publishers, Newyork, 2004.

[15] N. H. Vaidya, "TCP for Wireless and Mobile Hosts," MobiCom'99 Tutorial, Texas A\&M University, 1999

[16] Prof. Jitendranath Mungara Dr.S.P. Setti Prof.G. Vasanth, "New Model for Quality of Service in Mobile Ad Hoc Network", IJCSNS International Journal of Computer Science and Network Security, VOL.9 No.12, December 2009, pp 174-180.

[17] Romit Roy Choudhury, Xue Yang, Nitin H. Vaidya , Ram Ramanathan, "Media Access Control for Ad Hoc Networks: Using directional antennas for medium access control in ad hoc networks", ACM MobiCom, September 2002, pp. 59 70.

[18] Song Guo and Oliver Yang, "Minimum Energy Multicast Routing for Wireless Ad-hoc Networks with Adaptive Antennas", IEEE International Conference on Network Protocols (ICNP'04), 2004.

[19] URL: http://www.isi.edu/nsnam/ns/. Page accessed on February $9^{\text {th }}, 2010$.

[20] W. R. Stevens. "TCP/IP Illustrated, Volume 1" Addison Wesely, 1994.

[21] Wikipedia, the free encyclopedia. http://en.wikipedia.org/wiki/802.11, Page accessed January 2010. 